\title{
EFFECT OF ZINC OXIDE NANOPARTICLES ON NEUROBLASTOMA SH-SY5Y CELLS
}

\author{
${ }^{1}$ Jinghui Zheng, ${ }^{1}$ Theresia Schnurr, ${ }^{1,2}$ Kriya Dunlap, ${ }^{3}$ Deben Das and ${ }^{1,2}$ Lawrence Duffy \\ ${ }^{1}$ Department of Chemistry and Biochemistry, \\ ${ }^{2}$ Institute of Arctic Biology, \\ ${ }^{3}$ Department of Mechanical Engineering, \\ University of Alaska Fairbanks, Fairbanks, AK 99775, USA
}

Received 2014-01-08; Revised 2014-05-07; Accepted 2014-07-04

\begin{abstract}
The Arctic and sub-arctic regions are impacted by the growth of the global nanotechnology industry and the transport of chemicals to the North. New nanotechnology industries, such as neural prothesis, are bringing nanomaterials in direct contact with neurons and glial cells. Nanomaterials have unique chemical and physical properties that may lead to toxicological effects by interfering with normal cellular metabolism. Zinc Oxide Nanoparticles (ZnO NPs) are now very common and widely used in daily life. Over the last decade there have been reports that $\mathrm{ZnO}$ NPs can have negative impacts on plants and simple organisms. However, there is a paucity of research on the effects and mechanisms by which ZnO NPs impact neuronal cells. This report investigates how ZnO NPs interact with the neuroblastoma cell line SH-SY5Y. Using transmission electron microscopy, we observed that the ZnO NPs form $36 \mathrm{~nm}$ particles, on average and increased the level of the cytokine VEGF in extracellular fluid. Moreover, ZnO NPs, in presence of TNF- $\alpha$, decreased the level of extracellular VEGF when compared with TNF- $\alpha$ treatment alone. These findings suggest a basis for further studies on the interactions of ZnO NPs with signal transduction pathways and their impact on the release of cytokines. The importance of developing cellular model systems to evaluate the toxicity of nanomaterials before they are released to the marketplace will benefit both the ecosystem and human health.
\end{abstract}

Keywords: Nonmaterials, ZnO Sh-SY5Y Cells, VEGF

\section{INTRODUCTION}

Nanoparticles (NPs) are particles with a diameter typically smaller than 100 nanometers $(\mathrm{nm})$ that differ from their bulk form (diameter $>1000 \mathrm{~nm}$ ) and usually have unique properties. Zinc oxide and carbon-coated titanium alloys are two examples of commonly used NPs (Yang et al., 2010). NPs are also used in the pharmaceutical field to develop substances for drug delivery (De Jong and Borm, 2008). This is especially true for the anticancer, anti-bacterial and anti-viral drug development industries. Although nanomaterials bring benefits, they also can have negative impacts on the ecosystem (Buzea et al., 2007). The NPs' unique surface properties (i.e., the charge and the reactivity) can lead to biological effects such as inflammation and brain cancer. Since some NPs can pass the blood brain barrier based on their small size (De Jong and Borm, 2008), they will have access to neurons. Several toxicological studies support the contention that airborne NPs with diameters of less than 10 microns are correlated with inflammatory effects (Dobrovolskaia et al., 2008; Borm et al., 2006).

$\mathrm{ZnO}$ NPs are one of the common metal nano materials in current use. In the construction industry, $\mathrm{ZnO}$ NPs are used to coat wood, plastic or textiles to AK 9977575, USA, Tel: 907-474-7525 Fax: 907-474-5101 
protect them from exposure to UV light. In the cosmetic field, $\mathrm{ZnO}$ NPs are an essential element in sunscreens. While ZnO NPs are known for their diverse properties, only in the last decade have NPs been studied for their toxicity (Nowack and Buchelli, 2007). Kumari et al. (2011) have found that ZnO NPs can act as clastogenic and cytotoxic agents when NPs come into contact with common onion root cells. NPs have been found to be toxic not only in plants cells, but also in animals. Bai et al. (2010) found that ZnO NPs are toxic to the zebrafish embryos. Specifically, the research found that $30 \mathrm{~nm}$ nanoparticles form aggregates of different sizes during the exposure process and induced embryonic mortality. In addition, the high concentrations of ZnO NPs decreased the embryos' hatching rate. Exposure to $\mathrm{ZnO}$ NPs also shortened the body length of larvae and induced tail malformation as the concentration increased (Bai et al., 2010).

Cytokines are a group of proteins that play an important role in cell signaling in higher vertebrates. Upon cellular stimulation, cytokine levels increase in plasma after trauma or infection and are used as biomarkers by clinicians to monitor for inflammation (Hopkins et al., 2012; Kemp et al., 2005; Fava et al., 1994). Cytokines, such as Interlukin-1 (IL-1) and Tumor Necrosis Factor- $\alpha$ (TNF- $\alpha)$, are involved in the immune response to infection and are characterized as proinflammatory (Boyle, 2005). Production of the proinflammatory cytokines has been associated with tumor growth in neoplasms (Duffy et al., 2011) and the IL-1 family is important in both acute and chronic inflammation. IL-1 receptor binding induces the activation of transcription factors and the expression of genes that promote the production of other cytokines as well as growth factors, such as Vascular Endothelial Growth Factor (VEGF). VEGF is expressed by rodent and human tumor cells (Kemp et al., 2005; Roskoski, 2007; Duffy et al., 2011). VEGF expression has been found in activated macrophages (Fava et al., 1994), keratinocyte (Brown et al., 1992b), renal glomerular visceral epithelium and mesangial cells (Brown et al., 1992a; Iijima et al., 1993), hepatocytes (Monacci et al., 1993); smooth muscle cells (Ferrara et al., 1991), embryonic fibroblasts, bronchial, choroid plexus epithelia cells (Pertovaara et al., 1994; Breier et al., 1992; Cao et al., 1996 ) as well as neurons and glial cells (Storkebaum and Carmeliet, 2004). In vivo, VEGF can induce angiogenesis, a process that is associated with wound healing, embryonic development and the growth and metastasis of solid tumors, as well as an increase in microvascular permeability (Kemp et al., 2005). Based on all the factors listed above, VEGF is an important signaling molecule in inflammation and angiogenesis. Elevated levels of VEGF have been reported in synovial fluids of rheumatoid arthritis patients and in sera from cancer patients (Koch et al., 1994; Senger et al., 1993; Kondo et al., 1994). Based on this background, our goal was to develop a cell culture system to study the effect of $\mathrm{ZnO}$ nanoparticles on a neuronal neuroblastoma cell line which secretes VEGF. We asked two main questions: (1) Do ZnO NPs have a uniform and stable size in our cell culture system and (2) will $\mathrm{ZnO} \mathrm{NP}$ exposure impact the release of VEGF by $5 \mathrm{H}-\mathrm{SY} 5 \mathrm{Y}$ cells?

\section{MATERIALS AND METHODS}

\subsection{Human SH-SY5Y Cell Culture}

Human SH-SY5Y neuroblastoma cells were grown from the frozen cells which were stored in liquid nitrogen, then thawed into $100 \mathrm{~mm}$ dishes (Falcon) containing: High-glucose DMEM (pH 7.4), 10\% Fetal Bovine Serum (FBS), $3.7 \mathrm{~g} \mathrm{~L}^{-1}$ sodium bicarbonate, $100 \mathrm{U} \mathrm{mL}^{-1}$ of penicillin and streptomycin and $1 \%$ GlutaMax-1 (GM). Cultures were incubated in a humidified atmosphere with $5 \% \mathrm{CO}_{2}$ at $37^{\circ} \mathrm{C}$. After one week of incubation, cells were detached using 0.5 $\mathrm{mg} \mathrm{mL} \mathrm{m}^{-1}$ trypsin $\left(5 \mathrm{~min}\right.$ and $\left.37^{\circ} \mathrm{C}\right)$, collected by centrifugation $(1,200 \mathrm{rpm})$ and plated into six-well plates. After a week of incubation in the six-well plates, the media was replaced with serum-free media for the assay. All experiments were carried out $24 \mathrm{~h}$ after depriving the neuron cultures of serum (Gustafson et al., 2012).

\subsection{Light Microscopy of SH-SY5Y Cell}

After one week's growth in a six-well plate, neuroblastoma cells were observed under the Nikon Eclipse TE 2000U inverted microscope to assess the normal condition of the cells. Morphology changes after the treatments were noted. Normal morphology shows asymmetric cells with processes.

\subsection{Transmission Electron Microscopy}

Transmission Electron Microscopy (TEM, JEOL 1200) was used to detect the morphology characteristics of ZnO NPs. ZnO NPs were mixed with 
Propylene Glycol (PG) in a 1:9 PG ratio $(10 \mu \mathrm{L}$ of NPs and $90 \mu \mathrm{L} \mathrm{PG})$ for a $10 \%$ final solution. $5 \mu \mathrm{L}$ of prepared $\mathrm{ZnO}$ NPs solutions were pipetted on to the TEM grid and after 20s, were blotted off the SEM grid, then $5 \mu \mathrm{L}$ of DI water was placed on the grid for $20 \mathrm{~s}$ and blotted from the grid. After repeating 3 times, the grid was dried overnight. The grid of $\mathrm{ZnO}$ NPs was examined after one day.

\subsection{BCA Protein Assay}

The BCA protein assay (Pierce) is commonly used to determine protein content in samples. It is a detergent compatible formulation based on bicinchoninic acid for the colorimetric detection and quantitation for total protein in the samples. The assay is based on the principle that $\mathrm{Cu} 2+$ is reduced to $\mathrm{Cu} 1+$ by protein in an alkaline medium which is called the biuret reaction. The reaction is detected with a highlysensitive and selective colorimetric detection of the $\mathrm{Cu} 1+$ using a unique reagent containing bicinchoninic acid. The final color of the solution will be purple and depends on the concentration of proteins existing in samples. The colors can also appear in different shades. The purple color is caused by the chelation of two molecules of bicinchoninic with one $\mathrm{Cu}+$.

\subsection{VEGF Assay}

The human VEGF ELISA assay ( $\mathrm{R}$ and D System) was used for measurements of extra and intracellular VEGF from cultured human SH-SY5Y cells. By following published directions ( $\mathrm{R}$ and $\mathrm{D}$ Systems), VEGF was detected in a colorimetric change plate. A Beckman-Coulter Multimode DTX 880 multi-plate reader detected the color change at an absorbance $\lambda=$ $450 \mathrm{~nm}$. After ZnO NPs and TNF- $\alpha$ treatments, the media was directly removed and utilized for the extracellular assay. The same remaining cells were rinsed with PBS. Cells were removed from the plates by scraping in ice-cold PBS, collected in Eppendorf tubes and sonicated for $5 \mathrm{sec}$.

\subsection{Statistical Analysis}

Data was analyzed using GraphPad Prism, statistical software (version 5.0) to evaluate significance between treatments. The difference between treatments was evaluated using an unpaired student's t-test. Differences were considered significant at the $\mathrm{p}<0.05$. All data are reported as means +or-SD.

\section{RESULTS}

\subsection{Nanoparticle Shape}

The size and shape of the ZnO NPs was observed using Transmission Electron Microscopy (TEM) at several magnifications. $\mathrm{ZnO} \mathrm{NPs}$ tended to form aggregates in aqueous environments which is consistent with other ZnO NPs morphology studies (Fig. 1).

The ZnO NPs tended to form aggregates; but most individual particle's size was smaller than $100 \mathrm{~nm}$. Any effects of $\mathrm{ZnO}$ on the cell will be caused by its NPs form, not its larger Fine form in which particle diameters are between 100 and $1000 \mathrm{~nm}$, or its Bulk form in which the particle diameter is larger than 1000 nm (Fig. 2).

The general morphology of ZnO NPs under the 500,000 magnification illustrates that ZnO NPs show elongated-type shapes: Oval; rectangular-elongated shape and round shape. The darker color of ZnO NPs in Fig. 2 indicates that $\mathrm{ZnO}$ NPs are overlapping. When magnification was expanded as seen in Fig. 3, the definition of these elongated $\mathrm{ZnO}$ NPs was more evident and the average size was estimated to be $36 \mathrm{~nm}$. These particles exist within a narrow range size. The individual particle diameter is smaller than $100 \mathrm{~nm}$. All these size characteristics, including the potential to aggregate over time, will impact their interactions with SH-SY5Y cells.

\subsection{Cell Viability}

The morphology of SH-SY5Y cells under 20X magnification after $24 \mathrm{~h}$ (in a serum-free media) demonstrates that the cells remained healthy. The cells maintained their projections and shape. Figure 4a illustrates the normal morphology of the cells in a serum-free media before treatment with $\mathrm{ZnO}$ NPs.High concentration of ZnO NPs after $24 \mathrm{~h}$. of

$\mathrm{ZnO}$ NPs treatment led to complete mortality of the cells. A series of concentrations and time-dependent experiments were then used to define conditions for observing impacts of $\mathrm{ZnO}$ NPs. Figure $4 \mathbf{b}$ shows the morphology of SH-SY5Y under 20X after $1 \mathrm{~h}$. of 0.40 $\mu \mathrm{L} \mathrm{mL} \mathrm{m}^{-1} \mathrm{ZnO}$ NPs treatment. The numbers of axon projection were reduced and some cells changed morphology to a rounded shape. After $4 \mathrm{~h}$, the morphology of SH-SY5Y of $5 \mu \mathrm{L} \mathrm{mL}{ }^{-1} \mathrm{ZnO}$ NPs treatment showed that most cells lost their normal morphology and axon projections. There was almost complete disappearance of connectivity between cells (Fig. 4). 


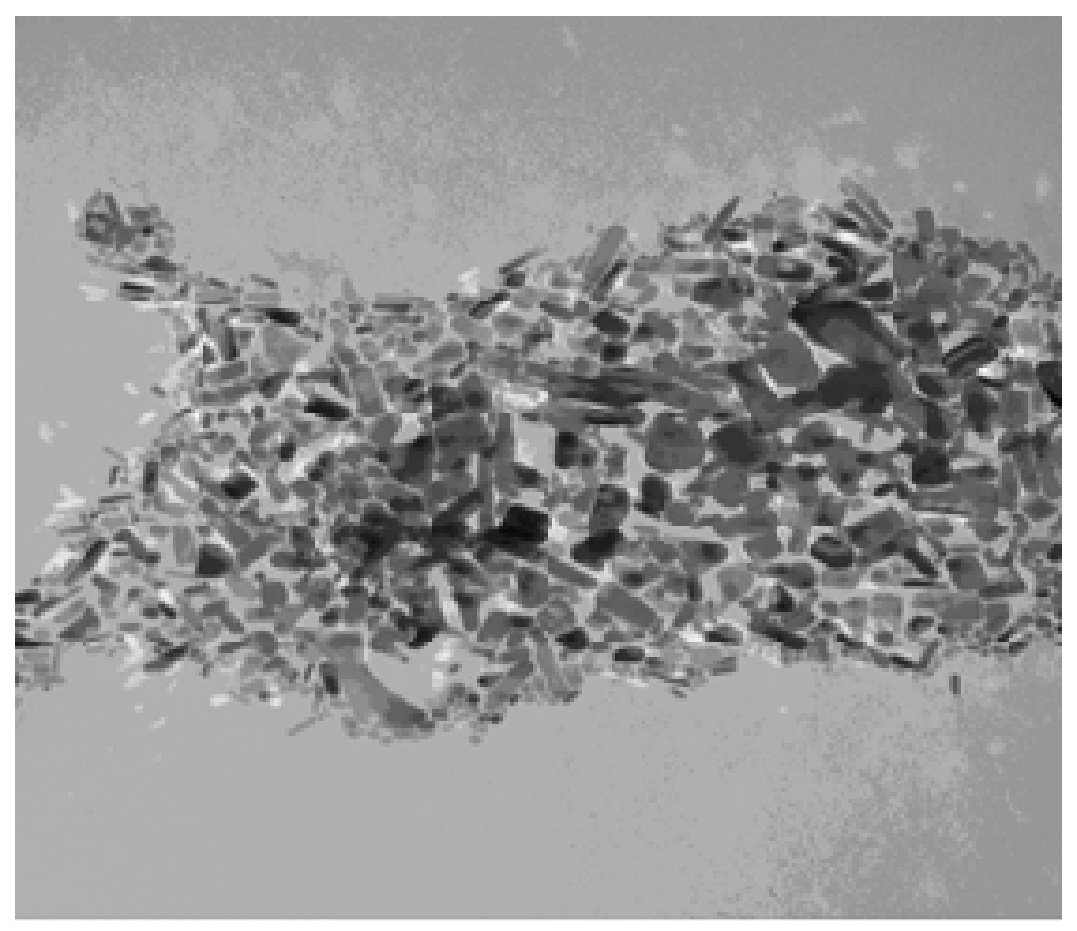

Fig. 1. ZnO NPs morphology under 100,000X

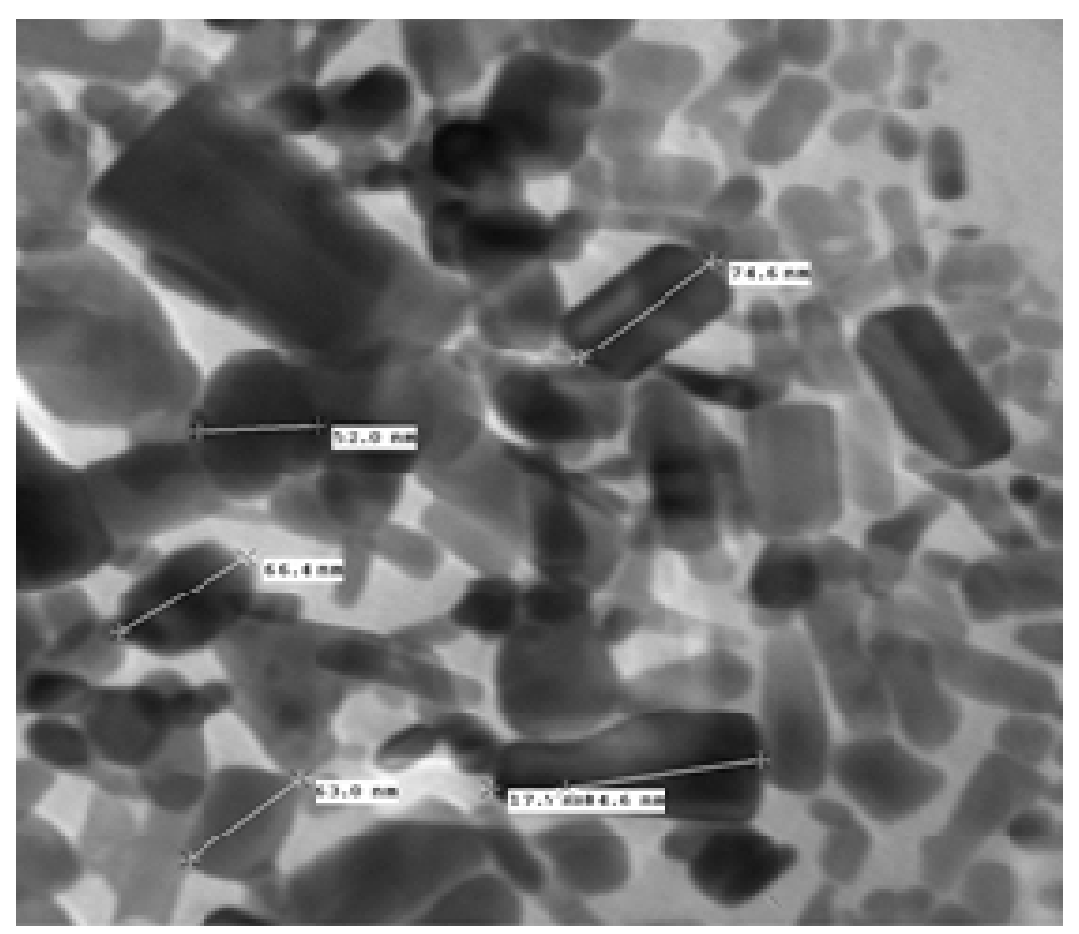

Fig. 2. ZnO NPs morphology under 300,000X 


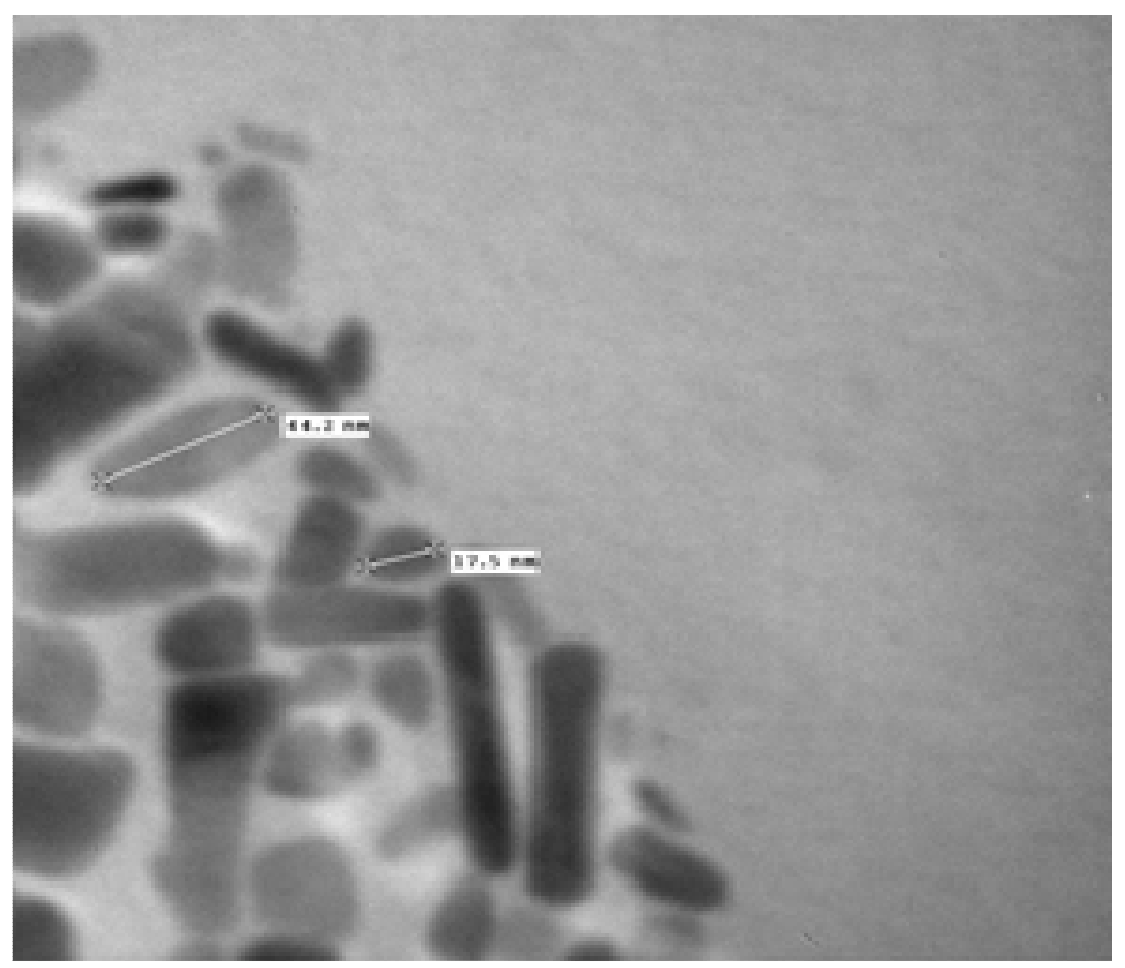

Fig. 3. ZnO NPs morphology under 500,000X

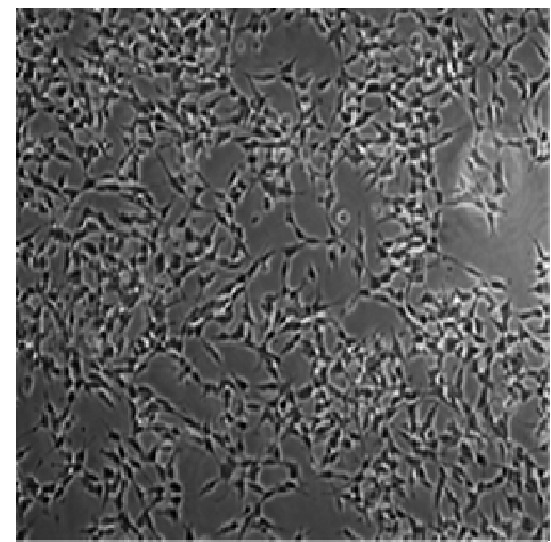

(a)

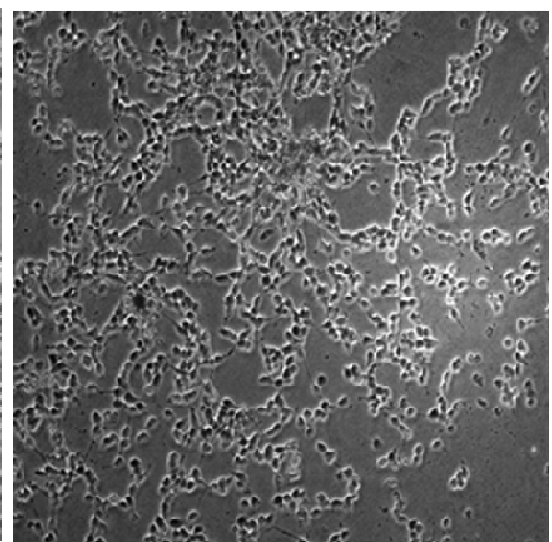

(b)

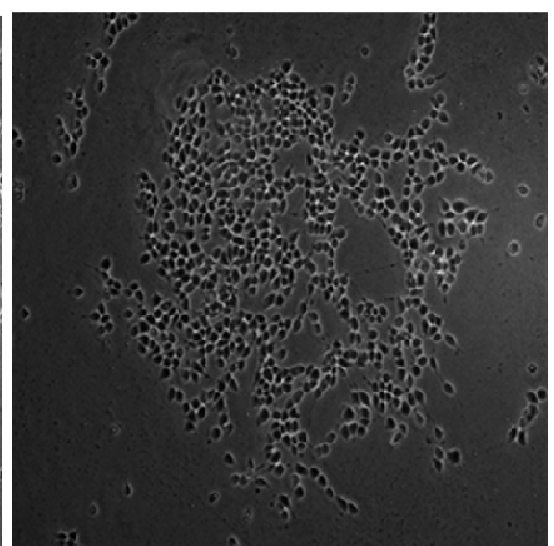

(c)

Fig. 4. (a) SH-SY5Y in serum free cell culture 4 (b) SH-SY5Y in ZnO NPs exposure (1h) (c) SH-SY5Y cell culture in ZnO NPs exposure $(4 \mathrm{~h})$

\subsection{VEGF Secretion}

The level of VEGF extracellular secretion is dependent on incubation timing with TNF- $\alpha$ (Fig. 5). This is expected because the longer the exposure time the more the VEGF will be released into the culture. This data shows that VEGF release under the TNF-stimulation is a time-dependent behavior, the longer the exposure time, the more VEGF has been induced and secreted. These results are also consistent with previously reported results (Duffy et al., 2011), that a 30 min TNF- $\alpha$ incubation increases the extracellular VEGF level in culture media. 
In Fig. 6, the $30 \min$ TNF- $\alpha\left(2.5 \mu \mathrm{L} \mathrm{mL} L^{-1}\right)$ treatment is shown as a baseline stimulation and positive control. The level of VEGF release after $\mathrm{ZnO}$ NPs $\left(5 \mu \mathrm{L} \mathrm{mL} \mathrm{m}^{-1}\right)$ for $4 \mathrm{~h}$ and followed by a $30 \mathrm{~min}$ TNF- $\alpha\left(2.5 \mu \mathrm{L} \mathrm{mL}^{-1}\right)$ treatment showed a significant reduction in VEGF release. This result indicates the
ZnO NPs can interfere at the molecular level with the cellular cytokine signal transduction pathways. The effects of stressors, either cytokines or toxicants, can be additive, subtractive or synergistic. The inhibiting behavior in Fig. 6 suggests that the effect of $\mathrm{ZnO}$ NPs on TNF- $\alpha$ stimulation appears to be subtractive.

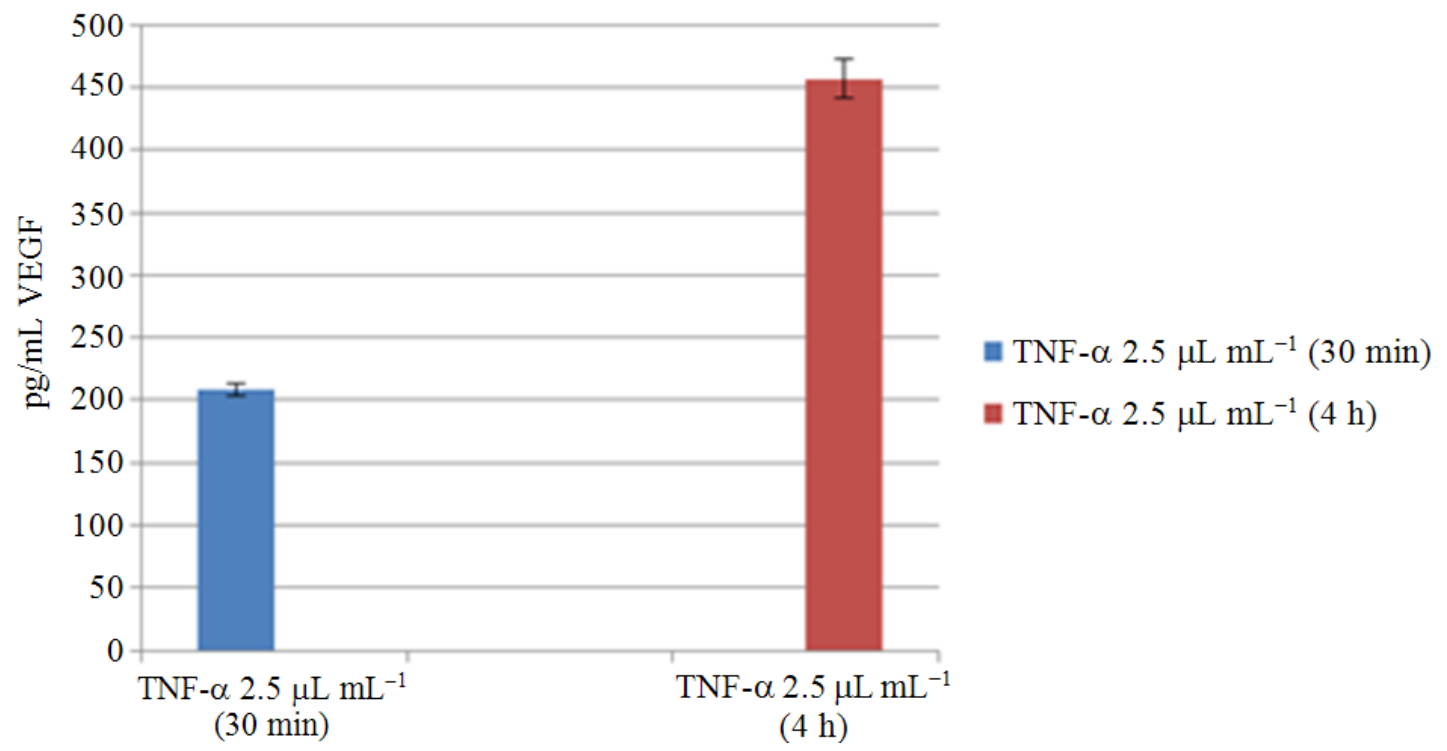

Fig. 5. VEGF extracellular releases after TNF- $\alpha$ treatments. Assessment of the VEGF extracellular releases after TNF- $\alpha$ treatments in SH-SY5Y cells. Cells were exposed to $2.5 \mu \mathrm{L} \mathrm{mL} \mathrm{m}^{-1} \mathrm{TNF}-\alpha$ for $30 \mathrm{~min}$ and $4 \mathrm{~h}$. The methodology for assessment of the VEGF extracellular releases is described in Materials and Methods. Data are representative of three separate experiments. $(\mathrm{p}<0.05, \mathrm{t}$-test $)$

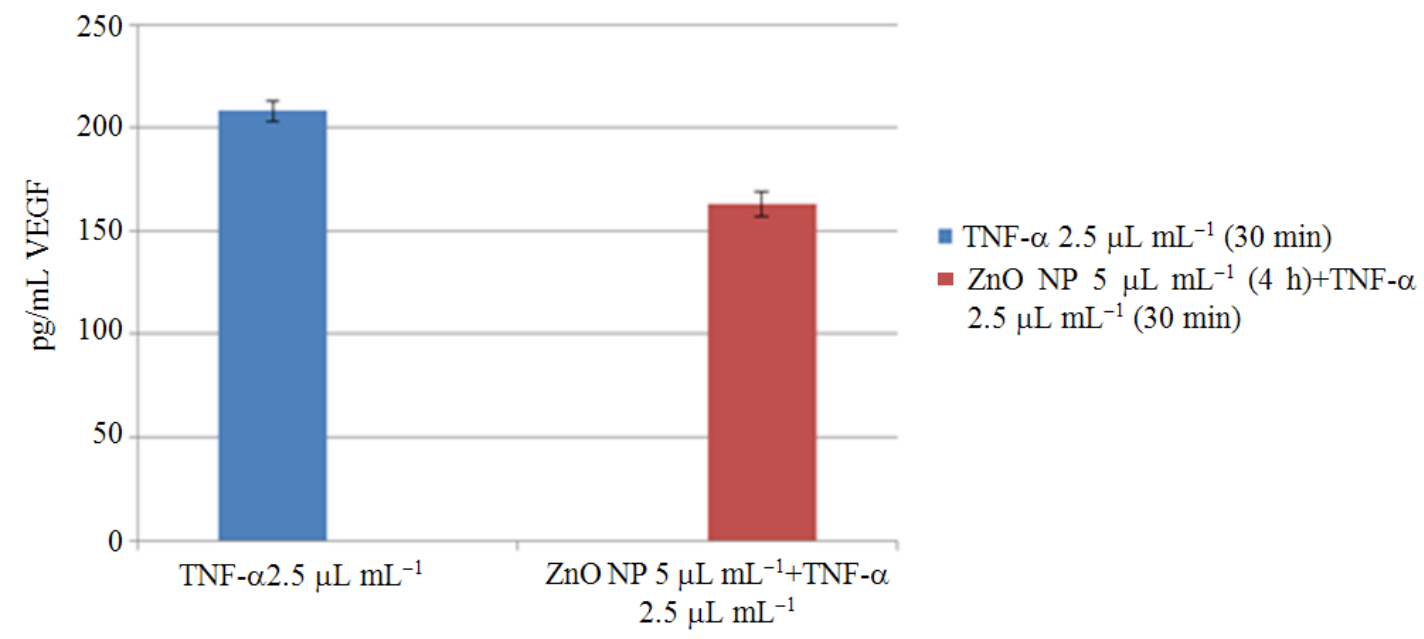

Fig. 6. VEGF extracellular releases after combining TNF- $\alpha$ and $\mathrm{ZnO}$ NPs treatments. Cells were exposed to $2.5 \mu \mathrm{L} \mathrm{mL}^{-1}$ TNF- $\alpha$ for $30 \mathrm{~min}$ or $5 \mu \mathrm{L} \mathrm{mL} \mathrm{LnOP}^{-1} \mathrm{ZnOr} 4 \mathrm{~h}$ plus an additional $2.5 \mu \mathrm{L} \mathrm{mL} \mathrm{mL}^{-1} \mathrm{TNF}-\alpha$ for $30 \mathrm{~min}$. The methodology for assessment of the VEGF extracellular releases is described in Materials and Methods. Data are representative of three separate experiments. $(\mathrm{p}<0.05$, t-test $)$ 


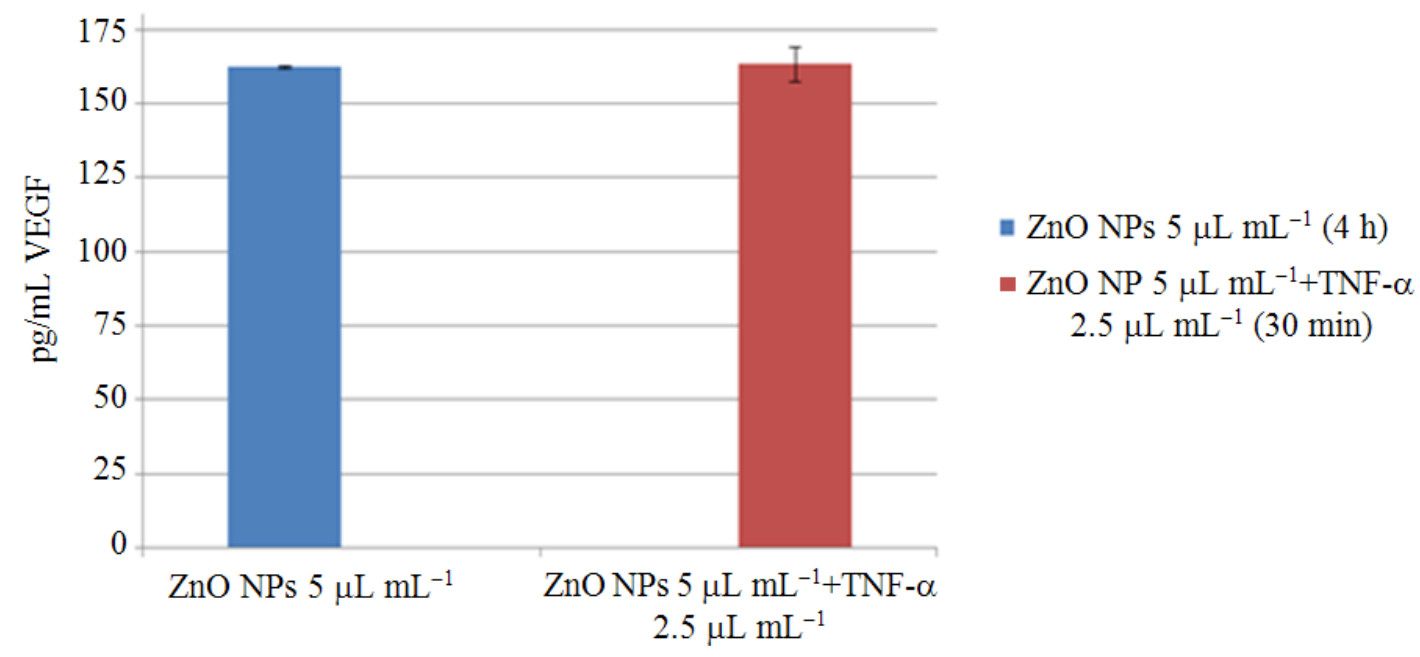

Fig. 7. VEGF extracellular releases after combining ZnO NPs and TNF- $\alpha$ treatments. Assessment of the VEGF extracellular releases after combining ZnO NPs and TNF- $\alpha$ treatments in SH-SY5Y cells. Cells were exposed to $5 \mu \mathrm{L} \mathrm{mL} \mathrm{mL}^{-1} \mathrm{ZnO}$ NPs for $4 \mathrm{~h}$ or 5 $\mu \mathrm{L} \mathrm{mL}^{-1} \mathrm{TNF}-\alpha$ for $30 \mathrm{~min}$. The methodology for assessment of the VEGF extracellular releases is described in Materials and Methods. Data are representative of three separate experiments. ( $p>0.05$, t-test)

After 4h treatment with $\mathrm{ZnO}$ NPs $\left(5 \mu \mathrm{L} \mathrm{mL}^{-1}\right)$ alone or with TNF- $\alpha\left(2.5 \mu \mathrm{L} \mathrm{mL} L^{-1}\right)$ treatment, there was no significant difference in extracellular VEGF (Fig. 7). This result also suggests that pretreatment of $\mathrm{ZnO}$ NPs inhibits the TNF- $\alpha$ induction of VEGF.

\section{DISCUSSION}

$\mathrm{ZnO}$ NPs have been used in many products. Previous studies (Bai et al., 2010) show that the aggregation effects can increase the toxicity of $\mathrm{ZnO}$ NPs. Transmission Electron Microscopy data results in this research demonstrate that $\mathrm{ZnO} \mathrm{NPs}$ aggregate in solution and the average size of the particles is about $36 \mathrm{~nm}$. Moreover, these particles have a heterogeneous shape and therefore they may potentially affect neuronal cells differently. However, there is no previously reported research on these neuronal cells. Some research reported that the smaller the size of nanoparticles, the more toxic their behavior (Kumari et al., 2011; Bruneau et al., 2013).

VEGF is a signal protein that is produced by numerous types of cells and can be induced by other cytokines. VEGF can stimulate new blood vessels and lymphatic vessels to grow under normal conditions. When VEGF is over-expressed, it can contribute to diseases, especially cancer. In advanced cancer studies, researchers create VEGF-receptors antagonists to block the VEGF production in tumor cells (Kerbel, 2000).
Our research reveals that after $4 \mathrm{~h}$ incubations with $\mathrm{ZnO}$ NPs, the normal morphology of SH-SY5Ycells disappear. They lose their projections of axons and the interactions with nearby cells. The ELISA results show that $\mathrm{ZnO}$ NPs with a concentration of $5 \mu \mathrm{L} \mathrm{mL}{ }^{-1}$ increased the extracellular VEGF production after $4 \mathrm{~h}$ incubation. In comparison, an exposure to TNF- $\alpha$, with a concentration of $2.5 \mu \mathrm{L} \mathrm{mL}-1$, increased the extracellular VEGF production by about three-fold.

In addition, we studied the combined effects of $\mathrm{ZnO}$ NPs and TNF- $\alpha$ to SH-SY5Y cells on VEGF secretion. The results show that the extracellular VEGF production is almost the same under $\mathrm{ZnO}$ NPs and $\mathrm{ZnO}$ NPS+TNF- $\alpha$ conditions (Fig. 7). The ZnO NPS+TNF- $\alpha$ treatment has less effect on extracellular VEGF production $(160 \mathrm{pg}$ $\mathrm{mL}^{-1}$ ) than the TNF- $\alpha$ treatment alone $\left(450 \mathrm{pg} \mathrm{mL}^{-1}\right)$. This result has two possible explanations (1) the ZnO NPs can inhibit the release of VEGF in the presence of TNF- $\alpha$, which can be used in the development of a potential cancer drug or (2) the $\mathrm{ZnO}$ NPs killed the cells before they could release more VEGF into media. The second explanation needs further investigation because of a reduction in cellular protein content in $\mathrm{ZnO}$ NPs treated cells.

\section{CONCLUSION}

This research suggests that the ZnO NPs may interfere with the TNF- $\alpha$ regulating pathway (Fig. 8). This interference leads to reduction in the TNF- $\alpha$ stimulated release of VEGF. 


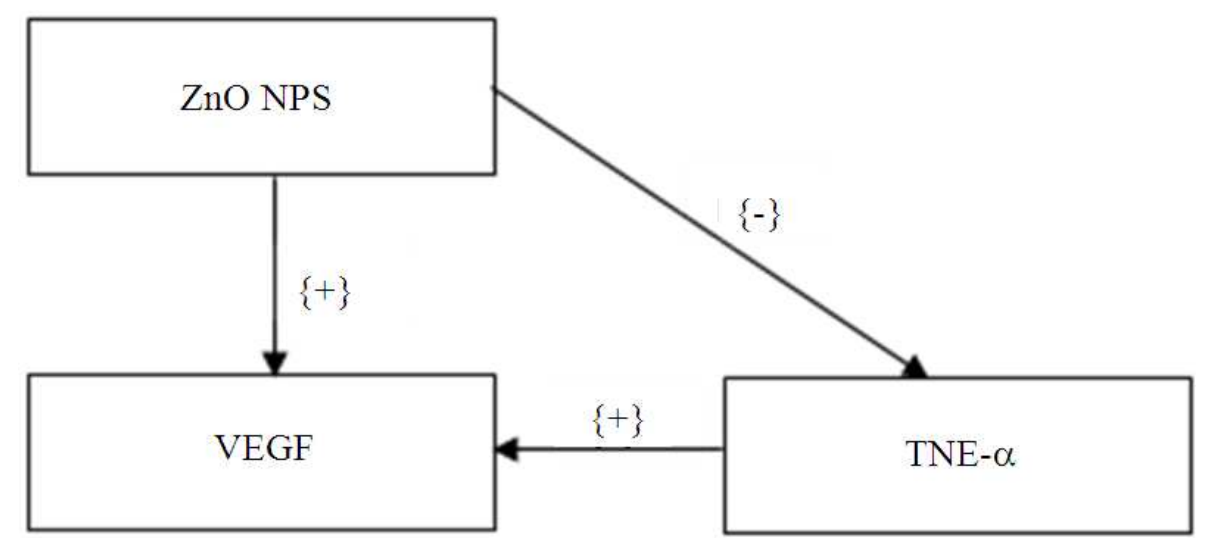

Fig. 8. Schematic diagram shows potential interactions between signal transduction pathways involved in VEGF release.g

\section{ACKNOWLEDGEMENT}

We gratefully acknowledge helpful discussions with Mary van Muelken. This research was partially funded by the National Institute of Neurological Disease and Stroke 2U54-NS041069-10

\section{REFERENCES}

Bai, W., Z. Zhang, W. Tian, X. He and Z. Chai et al., 2010. Toxicity of zinc oxide nanoparticles to zebrafish embryo: A physicochemical study of toxicity mechanism. J. Nanoparticle Res., 12: 16451654. DOI: $10.1007 / \mathrm{s} 11051-009-9740-9$

Breier, G., U. Albrecht, S. Sterrer and W. Risau, 1992. Expression of vascular endothelial growth factor during embryonic angiogenesis and endothelial cell differentiation. Development, 114: 521-532. PMID: 1592003

Borm, P.J., D. Robbins, S. Haubold, T. Kuhlbusch and H. Fissan et al., 2006. The potential risks of nanomaterials: A review carried out for ECETOC. Particle Fibre Toxicol., 3: 11. DOI: 10.1186/17438977-3-1

Boyle, J.J., 2005. Macrophage activation in atherosclerosis: Pathogenesis and pharmacology of plaque rupture. Curr. Vasc. Pharmacol., 3: 63-68. DOI: $10.2174 / 1570161052773861$

Brown, L.F., B. Berse, K. Tognazzi, E.J. Manseau and S. Rosen et al., 1992a. Vascular permeability factor MRNA and protein expression in human kidney. Kidney Int., 42: 1457-1461. DOI: 10.1038/ki.1992.441
Brown, L.F., K.T. Yeo, B. Berse, T.K. Yeo and L. van de Water et al., 1992b. Expression of vascular permeability factor (vascular endothelial growth factor) by epidermal keratinocytes during wound healing. J. Exp. Med., 176: 1375-1379. DOI: 10.1084/jem.176.5.1375

Bruneau, A., M. Fortier F. Gagne C. Gagnon P. Turcotte et al., 2013. Size distribution effects of cadmium tellurium quantum dots (CDS/CDTE) immunotoxicity on aquatic organisms. Environ. Sci. Processes Impacts, 15: 596-607. PMID: 23738358

Buzea, C., I.I. Pacheco and K. Robbie, 2007. Nanomaterials and nanoparticles: Sources and toxicity. Biointerphases, DOI: 10.1116/1.2815690

Cao, Y., H. Chen, L. Zhou, M.K. Chiang and B. AnandApte et al., 1996. Heterodimers of placenta growth factor/vascular endothelial growth factor. Endothelial activity, tumor cell expression and high affinity binding to Flk-1/KDR.. J. Biol. Chem., 271: 3154-3162. PMID: 8621715

De Jong, W.H. and P.J. Borm, 2008. Drug delivery and nanoparticles: Applications and hazards. Int. J. Nanomedicine, 3: 133-149. DOI: 10.2147/IJN.S596

Dobrovolskaia, M.A., P. Aggarwal, J.B. Hall and S.E. McNeil, 2008. Preclinical studies to understand nanoparticle interaction with the immune system and its potential effects on nanoparticle biodistribution. Molecular Pharmaceut., 5: 487-495. DOI: $10.1021 / \mathrm{mp} 800032 \mathrm{f}$

Duffy, L.K., L. Nicholas-Figueroa, K. L. Dunlap, 2011. Involvement of cytokine il-1ra in regulating the secretion of VEGF in SH-SY5Y neuroblastoma. Int. J. Bioinformat. Biotechnol., 1: 2251-3159. DOI: 10.5176/2251-3159_1.1.1 
Fava, R.A., N.J. Olsen, G. Spencer-Green, K.T. Yeo and L.F. Brown et al., 1994. Vascular permeability factor/endothelial growth factor (vpf/vegf): Accumulation and expression in human synovial fluids and rheumatoid synovial tissue. J. Exp. Med., 180: 341-346. DOI: 10.1084/jem.180.1.341

Ferrara, N., J. Winer and T. Burton, 1991. Aortic smooth muscle cells express and secrete vascular endothelial growth factor. Growth Factors, 5: 141-148. DOI: 10.3109/08977199109000278

Gustafson, S.J., K.L. Dunlap, C.M. McGill and T.B. Kuhn, 2012. A nonpolar blueberry fraction blunts NADPH oxidase activation in neuronal cells exposed to tumor necrosis factor-alpha. Oxidative Med. Cellular Longevity, 2012: 768101. DOI: 10.1155/2012/768101.

Hopkins, S.J., C.J. McMahon, N. Singh, J. Galea and P.J. Tyrrel et al., 2012. Cerebrospinal fluid and plasma cytokines after subarachnoid haemorrhage: CSF interleukin-6 may be an early marker of infection. J. Neuroinflammation. DOI: 10.1186/1742-2094-9-255.

Iijima, K., N. Yoshikawa, D.T. Connolly and H. Nakamura, 1993. Human mesangial cells and peripheral blood mononuclear cells produce vascular permeability factor. Kidney Int., 44: 959-966. DOI: 10.1038/ki.1993.337

Kemp, S.W., A.J. Reynolds and L.K. Duffy, 2005. Gender differences in baseline levels of vascular endothelial growth factor in the plasma of alaskan sled dogs. Am. J. Biochem. Biotechnol., 1: 111-114. DOI: $10.3844 /$ ajbbsp.2005.111.114

Kerbel, S.R., 2000. Tumor angiogenesis: Past, present and the near future. Carcinogenesis, 21: 505-515. DOI: $10.1093 /$ carcin/21.3.505

Koch, A.E., L.A. Harlow, G.K. Haines, E.P. Amento and E.N. Unemori, 1994. Vascular endothelial growth factor. A cytokine modulating endothelial function in rheumatoid arthritis. J. Immunol., 152: 4149-56. PMID: 7511670
Kondo, S., M. Asano, K. Matsuo, I. Ohmori and H. Suzuki, 1994. Vascular endothelial growth factor/vascular permeability factor is detectable in the sera of tumor-bearing mice and cancer patients. Biochim. Biophys. Acta, 1221: 211-214. PMID: 8148401

Kumari, M., S.S. Khan, S. Pakrashi, A. Mukherjee and N. Chandrasekaran, 2011. Cytogenetic and genotoxic effects of zinc oxide nanoparticles on root cells of allium cepa. J. Hazardous Mater., 190: 61321. DOI: 10.1016/j.jhazmat.2011.03.095

Monacci, W.T., M.J. Merrill and E.H. Oldfield, 1993. Expression of vascular permeability factor/vascular endothelial growth factor in normal rat tissues. Am. J. Physiol., 264: 995-1002. PMID: 8476026

Nowack, B. and D.T. Bucheli, 2007. Review: Occurrence, behavior and effects of nanoparticles in the environment. Environ. Poll., 150: 5-22. DOI: 10.1016/j.envpol.2007.06.006a

Pertovaara, L., A. Kaipainen, T. Mustonen, A. Orpana and N. Ferrara et al., 1994. Vascular endothelial growth factor is induced in response to transforming growth factor-beta in fibroblastic and epithelial cells. J. Biol. Chem., 269: 6271-6274. PMID: 8119973

Roskoski, J.R., 2007. Vascular Endothelial Growth Factor (VEGF) signaling in tumor progression. Oncol. Hematol., 62: 179-213. PMID: 17324579

Senger, D.R., L. Van de Water, L.F. Brown, J.A. Nagy and K.T. Yeo et al., 1993. Vascular Permeability Factor (VPF, VEGF) in tumor biology. Can. Metast. Rev., 12: 303-24. DOI: 10.1007/BF00665960

Storkebaum, E. and P. Carmeliet, 2004. Vegf: A critical player in neurodegeneration. J. Clin. Invest., 113: 14-8. DOI: $10.1172 / \mathrm{JCI} 20682$

Yang, Z., Z.W. Liu, R.P. Allaker, P. Reip and J. Oxford et al., 2010. A review of nanoparticle functionality and toxicity on the central nervous system. J. Royal Society, 7: S411-22. DOI: 10.1098/ rsif.2010.0158.focus 